\title{
Cardiac arrhythmia and myocardial ischaemia related to cocaine and alcohol consumption
}

\author{
Fiona Boag and C.W.H. Havard \\ Royal Free Hospital, Pond Street, London, NW3 2QG, UK.
}

\begin{abstract}
Summary: Following the drinking of $150 \mathrm{~g}$ of alcohol and a large amount of intra-nasal cocaine a previously healthy 31 year old man developed severe retrosternal pain and circulatory failure. An electrocardiogram showed supra-ventricular tachycardia with widespread ischaemic changes. Following electrical cardioversion electrocardiographic evidence of myocardial ischaemia persisted for $1 \mathrm{~h}$. Two days later basal and exercise electrocardiograms were normal. The combination of alcohol and cocaine may be life threatening.
\end{abstract}

\section{Introduction}

Cocaine inhibits the uptake of endogenously secreted catecholamines and thus acts as a sympathomimetic agent (Ritchie \& Cohen, 1975). It is therefore not surprising that its administration has been associated with ventricular arrhythmia and sudden death (Berchinal et al., 1978). Cocaine may also cause myocardial infarction through vasoconstriction of structurally normal coronary arteries (Schachne et al., 1984). Ethanol has been shown to stimulate the release of adrenaline and noradrenaline from the adrenal medulla (Perman, 1958) and to raise the serum concentration of free fatty acids (Shapiro et al., 1963). Acetaldehyde, the major metabolite of ethanol causes release of intra-myocardial noradrenaline (James \& Bear, 1967). Both these agents are thus arrhythmogenic. The use of cocaine as a stimulant in Western society is becoming more prevalent and the euphoriant effect is often enhanced by alcohol consumption. We report a patient with a life-threatening cardiac arrhythmia and myocardial ischaemia occurring after the consumption of alcohol and cocaine which suggests that the pharmacological interaction between cocaine and alcohol results in additive or even synergistic enhancement of the cardiovascular hazards.

\section{Case history}

A 31 year old fashion designer was admitted to hospital with severe angina. There was no previous or family history of cardiovascular disease. He smoked 20 cigarettes and drank 5 double whiskies a day and

Correspondence: F. Boag, M.R.C.P.

Accepted: 25 April 1985 took cocaine intra-nasally intermittently. On the night of admission he had consumed $400 \mathrm{ml}$ of whisky, $400 \mathrm{ml}$ of wine (a total of $150 \mathrm{~g}$ of alcohol) and he had taken a large amount of cocaine intra-nasally. On admission to hospital he was shocked, with a systolic pressure of $50 \mathrm{~mm} \mathrm{Hg}$, a diastolic blood pressure that was unrecordable and a pulse frequency greater than 200 beats/min. An electrocardiogram (ECG) showed supraventricular tachycardia with widespread ischaemic changes (Figure 1). The serum potassium was $3.6 \mathrm{mmol} / 1$. Electro-conversion restored sinus rhythm with a pulse frequency of $60 / \mathrm{min}$ but the ischaemic changes persisted for a further $1 \mathrm{~h}$ (Figure 2). Cardiac enzymes prior to cardioversion were normal. Serum potassium rose to $4.3 \mathrm{mmol} / \mathrm{l}$ without supplements. An exercise ECG was performed (Bruce protocol) $3 \mathrm{~d}$ later and stage 7 was reached without any ischaemic changes.

The patient has subsequently avoided excess alcohol, cocaine and cigarettes and has not had any further chest pain or arrhythmia.

\section{Discussion}

It is improbable that the ischaemic cardiac pain and the ECG changes would be precipitated by a short period of supraventricular tachycardia in a young man without ischaemic heart disease. It is therefore likely that coronary vasoconstriction was provoked by cocaine. The supraventricular tachycardia was almost certainly precipitated by the sympathomimetic effects of both drugs. It has been demonstrated that adrenaline decreases the myocardial refractory period and predisposes to atrial arrhythmias (Luck \& Engel, 


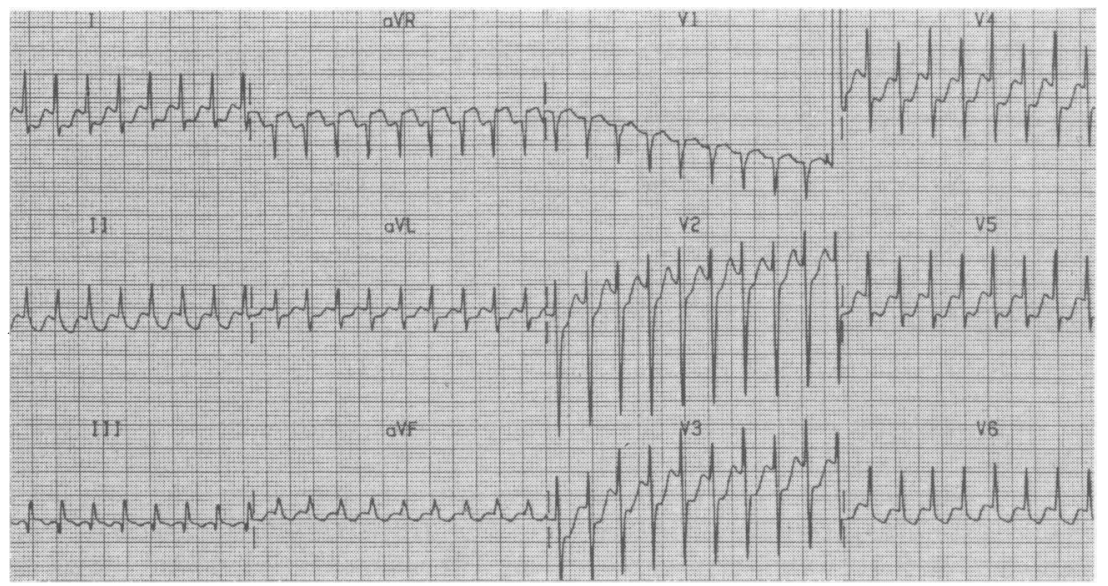

Figure 1 Supraventricular tachycardia with widespread ischaemic changes.

1983). Furthermore, catecholamines lower plasma potassium by stimulating beta adrenoreceptor linked $\mathrm{Na}^{+} \mathrm{K}^{+}$ATPase causing potassium influx into skeletal muscle, erythrocytes and possibly other tissues (Struthers \& Reid, 1984). It has also been shown that ethanol consumption raises the level of plasma free fatty acids (Shapiro et al., 1963) and this also predisposes the heart to arrhythmia (Tansay \& Opie, 1983). There has been an increase in cocaine-related deaths over recent years (Wetli \& Knight, 1979). Although $46 \%$ of these deaths have occurred after intravenous use of cocaine, $21 \%$ have followed intra-nasal installation.

The danger of combining alcohol with cocaine should be recognized, especially as the euphoric effect induced by both agents decreases the individual's ability to recognize illness and obtain help.

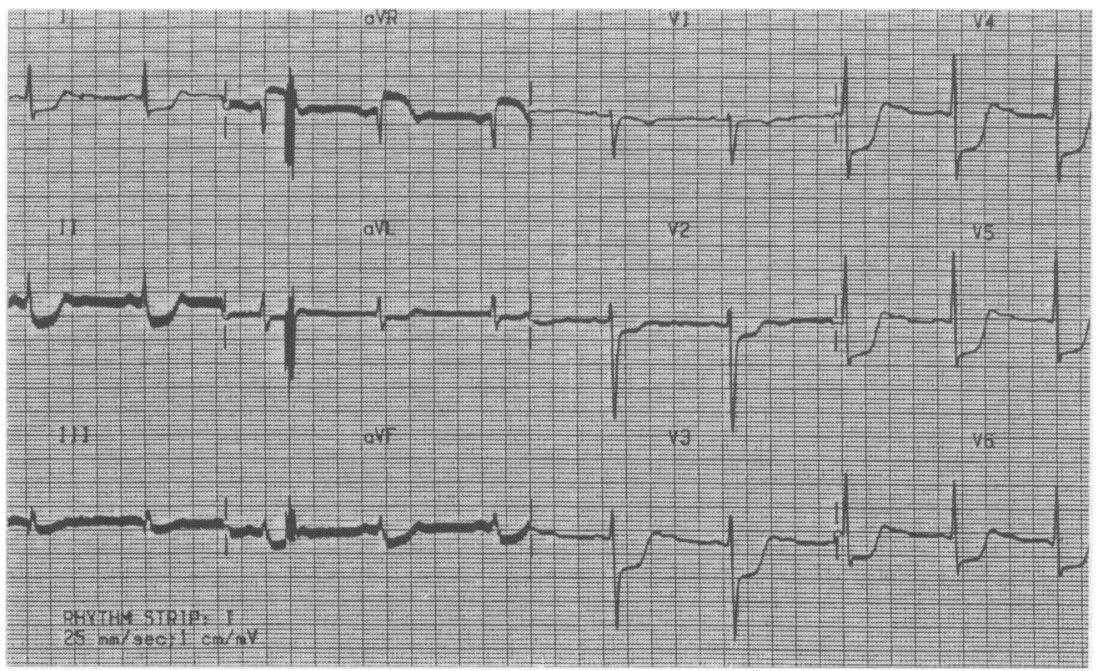

Figure 2 Post cardioversion. Ischaemic changes persisting. 


\section{References}

BERCHINAL, A., BARTALL, M. \& DESSER, K.B. (1978). Accelerated ventricular rhythm and cocaine abuse. Annals of Internal Medicine, 88, 519.

JAMES, T.N. \& BEAR, E.S. (1967). Effects of ethanol and acetaldehyde on the heart. American Heart Journal, 74, 243.

LUCK, J.C. \& ENGEL, J.R. (1983). Arrhythmias and social drinking. Annals of Internal Medicine, 98, 253.

PERMAN, E.S. (1958). The effects of ethyl alcohol on the secretion of the adrenal medulla in man. Acta Physiologica Scandinavica, 44, 241.

RITCHIE, J.M. \& COHEN, J. (1975). In The Pharmacological Basis of Therapeutics. 5th Ed., Goodman, L.S. \& Gilman, A. (eds). p. 379. Macmillan: New York.

SCHACHNE, J.S., ROBERTS, B.H. \& THOMPSON, P.D. (1984). Coronary artery spasm and myocardial infarction associated with cocaine use. New England Journal of Medicine, 310, 1665.

SCHAPIRO, R.H., DRUMMEY, G.D., SCHLEIG, R., MENDELSON, J.H. \& ISSELBACHER, K.S. (1963). Abnormalities of lipid transport accompanying prolonged alcohol ingestion in man. Gastroenterology, 44, 849.

STRUTHERS, A.D. \& REID, J.H. (1984). The role of adrenal medullary catecholamines in potassium homeostasis. Clinical Science, 66, 377.

TANSAY, M.J.B. \& OPIE, L.H. (1983). Relation between plasma free fatty acids and arrhythmias within the first twelve hours of acute myocardial infarction. Lancet, ii, 419.

WETLI, C.V. \& KNIGHT, R.K. (1979). Death caused by recreational cocaine use. Journal of the American Medical Association, 241, 2519. 